\title{
Are there decision support tools that might strengthen the health system for perinatal care in South African district hospitals? A review of the literature
}

Ntombifikile Maureen Nkwanyana* (i) and Anna Silvia Voce

\begin{abstract}
Background: South Africa has a high burden of perinatal deaths in spite of the availability of evidence-based interventions. The majority of preventable perinatal deaths occur in district hospitals and are mainly related to the functioning of the health system. Particularly, leadership in district hospitals needs to be strengthened in order to decrease the burden of perinatal mortality. Decision-making is a key function of leaders, however leaders in district hospitals are not supported to make evidence-based decisions. The aim of this research was to identify health system decision support tools that can be applied at district hospital level to strengthen decision-making in the health system for perinatal care in South Africa.
\end{abstract}

Methods: A structured approach, the systematic quantitative literature review method, was conducted to find published articles that reported on decision support tools to strengthen decision-making in a health system for perinatal, maternal, neonatal and child health. Articles published in English between 2003 and 2017 were sought through the following search engines: Google Scholar, EBSCOhost and Science Direct. Furthermore, the electronic databases searched were: Academic Search Complete, Health Source - Consumer Edition, Health Source - Nursing/ Academic Edition and MEDLINE.

Results: The search yielded 6366 articles of which 43 met the inclusion criteria for review. Four decision support tools identified in the articles that met the inclusion criteria were the Lives Saved Tool, Maternal and Neonatal Directed Assessment of Technology model, OneHealth Tool, and Discrete Event Simulation. The analysis reflected that none of the identified decision support tools could be adopted at district hospital level to strengthen decisionmaking in the health system for perinatal care in South Africa.

Conclusion: There is a need to either adapt an existing decision support tool or to develop a tool that will support decision-making at district hospital level towards strengthening the health system for perinatal care in South Africa.

Keywords: Decision support tool, Health system performance, Perinatal care, District hospital

\footnotetext{
* Correspondence: Nkwanyana@ukzn.ac.za

Discipline of Public Health Medicine, College of Health Sciences, University of

KwaZulu-Natal, George Campbell Building Room 215, Howard Campus,

Durban, KwaZulu-Natal Province, South Africa
}

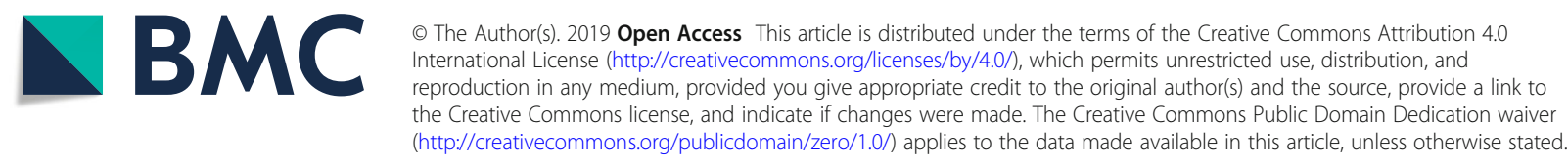




\section{Background}

The high rate of perinatal mortality is a global public health concern. Worldwide, there are approximately 4.6 million perinatal deaths every year with more than 1 million stillbirths occurring during the intrapartum period $[1,2]$. The majority of deaths occur in low- and middle-income countries (LMIC), with the rural poor most at risk [2-4]. Perinatal mortality imposes huge economic and psychosocial consequences on mothers and families $[5,6]$. Moreover, perinatal deaths have undesirable psychological effects on health care providers $[5,7$, 8]. The current state of perinatal outcomes calls for urgent implementation of evidence-based interventions in order to reduce the burden of perinatal deaths together with the associated adverse effects.

South Africa is a middle-income country with a high burden of perinatal deaths in spite of the availability of evidence-based interventions [9-12]. Specifically, out of 1000 births in the public sector, approximately 33 babies are born dead or die within the first 7 days of life, with most deaths being preventable [10]. Apart from the medical complications, such as spontaneous preterm labor and intrapartum asphyxia, health system administrative factors as well as health care provider-related problems are major contributors to perinatal deaths in South Africa [10, 12, 13]. Specifically, administrative factors contributing to perinatal mortality include inadequate equipment to provide optimal perinatal care, lack of transport and inadequate theatre facilities [14, 15]. Similarly, provider-related factors include failure to detect fetal distress, delay in referring patient for secondary treatment and delay in calling for expert advice $[14,15]$. Therefore, there is a need to strengthen the health system for perinatal care in South Africa in order to realize the potential impact of existing lifesaving interventions on perinatal outcomes $[9,11]$.

A majority of preventable perinatal deaths in the public sector in South Africa occur in district hospitals $[9,14]$. In addition, preventable perinatal deaths that occur in regional hospitals are often due to mismanagement around time of birth in district hospitals [9]. Most preventable perinatal deaths are associated with poor quality of care within poorly functioning health systems $[9,14]$. District hospitals do not always provide optimum maternity care and have challenges of staff incompetence as well as a shortage of essential equipment to provide safe perinatal care $[14,16]$. Therefore, the health system for perinatal care in district hospitals must be strengthened, as the site for intrapartum care for the majority of mothers who deliver in the public sector in South Africa [10, 11]. Essentially, focusing health system strengthening strategies on leadership in district hospitals should alleviate the burden of perinatal deaths in district hospitals, towards reducing perinatal deaths in South Africa $[9,17]$.
Setting priorities and allocating resources in a health system is a fundamental function of leadership. However, decisions pertaining to prioritizing areas of intervention in a health system towards improving health outcomes, taken by health facility managers in South Africa are rarely evidence-based $[18,19]$. Decision support tools, which are usually computer based information systems, have been developed to support decision processes in various organizations including the healthcare industry, and some have been found useful in prioritizing areas of intervention in health facilities in high-income countries. However, there is currently no identified decision support tool to assist hospital management teams to maximize the effectiveness of their decision processes in setting priorities and allocating resources. Hence, this study aimed to identify health system decision support tools that can be used at district hospital level to strengthen decision-making in the health system for perinatal care in South Africa.

\section{Methods \\ Aim}

The aim of the literature review was to identify tools that could support decision-making pertaining to prioritizing areas of intervention towards strengthening the health system for perinatal care in South Africa at district hospital level.

\section{Design}

A structured approach, the systematic quantitative literature review method [20,21], was conducted to find published articles on decision support tools that have been used to facilitate decision-making in health systems pertaining to perinatal, maternal, neonatal and child health.

\section{Methods}

Articles published in English were sought through the following search engines: Google Scholar, EBSCOhost and Science Direct. The electronic databases searched in EBSCOhost were "Academic Search Complete", "Health Source - Consumer Edition", "Health Source - Nursing/ Academic Edition' and "MEDLINE with Full Text". Journals searched in Science Direct included "Midwifery", "Public Health and Health Policy", "Obstetrics, Gynecology and Women" and "Perinatology, Pediatrics and Child Health". The following search terms were used to retrieve articles, "decision support tool - health system". In addition, the names of decision support tools identified from articles which met the inclusion criteria were also used as search terms. To ensure optimal coverage, additional articles were found within reference sections of retrieved articles. 


\section{Eligibility criteria} Inclusion criteria

Articles meeting the following criteria were included in the review:

1) Original research published in peer reviewed journals

2) Articles reporting on a decision support tool that was applicable to perinatal, maternal, child and neonatal health

3) Articles published in English from 2003 to 2017

\section{Exclusion criteria}

1) Articles reporting on decision support tools that were not applicable to perinatal, maternal, child and neonatal health

2) Articles reporting on clinical decision making algorithms

\section{Inclusion of online videos}

Online videos published by reputable organizations which detailed a description, development and or the application of identified decision support tools were included in the review.

\section{Assessment of publications}

Overall, the search yielded 6366 peer reviewed articles of which 5906 were excluded after screening article titles as they were either duplicates or not related to decision support tools to strengthen decision-making in a health system. Four hundred and sixty abstracts were screened to assess eligibility for inclusion in the review of which a majority were identified as literature review articles that described the basis of information on mortality estimates, risk factors, demography, intervention coverage as well as impact of several interventions on maternal, neonatal and child health, which has been pre-loaded in decision support tools. In total, the 385 articles which reported on the basis of pre-loaded information were excluded. Seventy-five full text articles were assessed for eligibility and 32 of these were not related to strengthening decision-making in a health system for maternal, neonatal and child health. Ultimately, 43 articles were eligible for inclusion in the literature review. The process of assessment of publications is presented in Fig. 1.

\section{Constructing the database}

A database of articles identified for the review was assembled. For each decision support tool identified, corresponding extracted articles were explored to recognize the following information: 1 ) the purpose of the decision support tool; 2) preloaded information in the decision support tool; 3) input required from a user prior to implementing the tool; 4) output generated by the tool; 5) assumptions, strengths and limitations of a tool; 6) socio-economic settings where the tool has been applied; and 7) the level of application in the health system. These features are described, for each decision support tool, in the Results section and are summarized in a tabular format.

\section{Results}

Forty-three articles which met the inclusion criteria for review detailed a description of the development of the tool and or the application of the tool. In total, four decision support tools were identified in the articles that met the inclusion criteria. These were: the Lives Saved Tool (LiST), Maternal and Neonatal Directed Assessment of Technology (MANDATE), OneHealth Tool $(\mathrm{OHT})$ and Discrete Event Simulation (DES) [22-25].

Table 1 presents a list of peer-reviewed literature that describes the development of the reviewed decision support tools. Table 2 presents a list of peer-reviewed literature in which the application of identified decision support tools have been reported. Online videos describing development and or application of the tools, derived from reputable websites, are listed in Table 3. The features for each decision support tool are summarized in Table 4.

Studies reporting description and or development of identified decision support tools were mainly conducted in high-income studies (HIC).

The Lives Saved Tool and the MANDATE model have been applied in low- and middle-income countries, whereas the DES has only been applied in high-income countries.

\section{Lives saved tool}

The Lives Saved Tool (LiST) assists users to estimate the impact of introducing or increasing the coverage of maternal, neonatal and child health interventions [23, 2527] The initial purpose of designing the LiST was to estimate the impact of scaling up community based interventions on under five mortality, and details of its construction were published as part of the Child Survival Series in 2003 [66]. Evaluated interventions included preventative programs such as availability of skilled attendant at birth, supply of measles vaccine, antenatal steroids, nevirapine and replacement feeding. Treatment programs evaluated included supply of vitamin A, antibiotics for pneumonia and newborn resuscitation [66]. Since its initial design, LiST has undergone further advancements, including the incorporation of the evaluation of the impact of facility based interventions aimed at improving maternal and birth outcomes, and at reducing neonatal mortality $[23,26]$. In 2008 , LiST was incorporated into the SPECTRUM software, hence LiST 


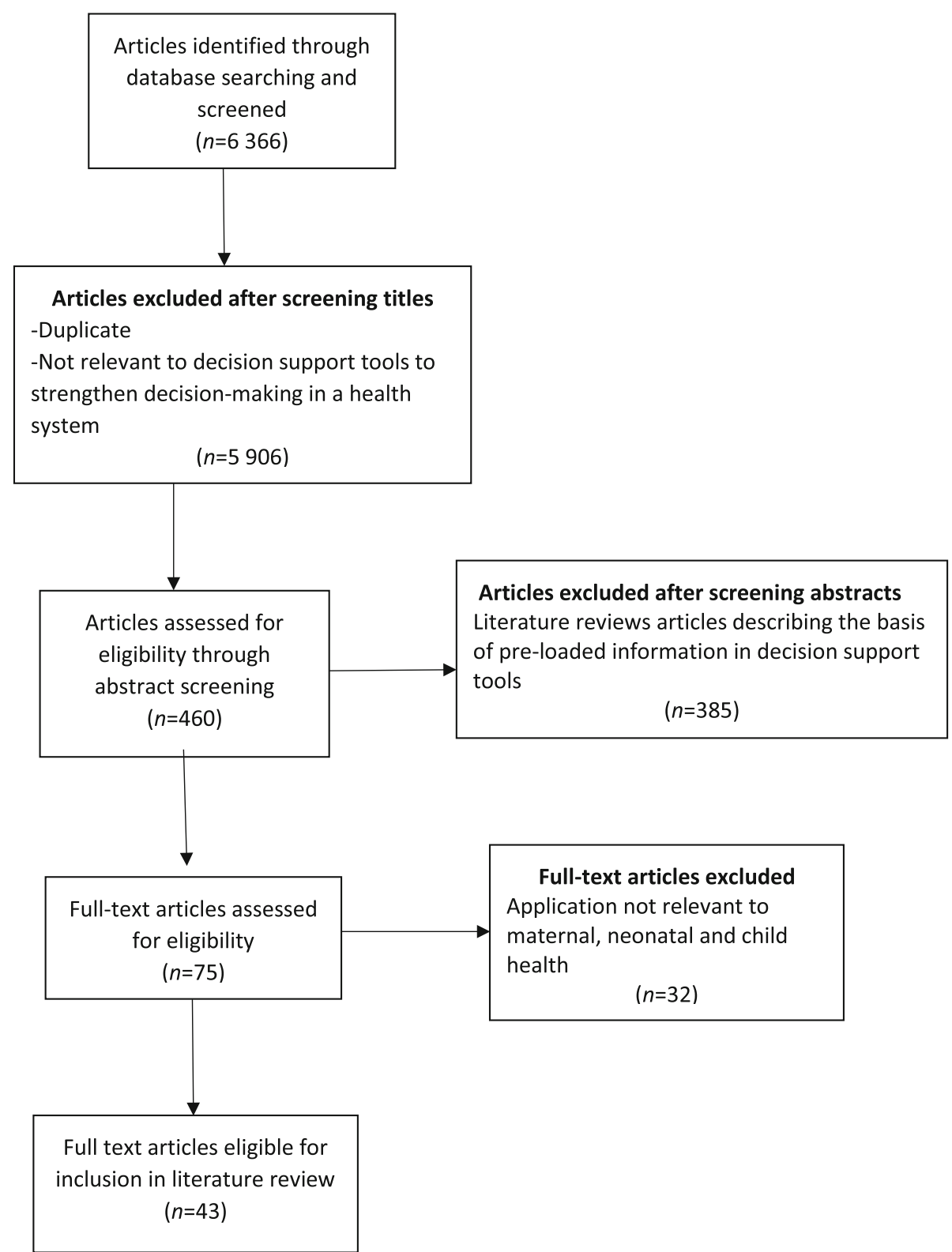

Fig. 1 Flow chart mapping out the number of articles identified, screened, excluded together with reasons for exclusion

utilizes data in the DemProj and Aids Impact Model (AIM) to generate the desired output [23]. The DemProj gives estimates of population size based on assumptions of fertility, mortality and migration for a country or a region [23]. The AIM estimates the impact of changes of Human Immunodeficiency Virus incidence, prevention and treatment measures on mortality [23]. Further additions have recently been made to LiST to enhance the accuracy of estimates of the cost implications of increasing coverage of interventions [30,35].

LiST is preloaded with a list of maternal, neonatal and child health interventions, which are relevant for implementation in LMIC [23, 26, 33]. The details of preloaded interventions include baseline coverage estimates of interventions at national level, together with recent estimates of the effectiveness of interventions [26, 27, 33$35,46]$. Furthermore, information on population risk factors and causes of death relating to maternal, neonatal and child health are preloaded in LiST [26, 34, 35]. A user needs to specify the geographical region where interventions will be applied, intended intervention coverage, measures of population health status, as well as an estimate of the effectiveness of the intervention when scaled up in order to generate an output to guide prioritization of interventions [26, 34, 38, 39, 42, 67, 68]. LiST gives an estimate of the number of lives that could 
Table 1 Author, year of publication and study location of reviewed journal articles that detail the description of the reviewed decision support tools for maternal and newborn healthcare

\begin{tabular}{|c|c|c|}
\hline Authors & $\begin{array}{l}\text { Year of } \\
\text { publication }\end{array}$ & Study Location \\
\hline \multicolumn{3}{|l|}{ Lives Saved Tool } \\
\hline Jones et al & 2003 & $\begin{array}{l}\text { United States of } \\
\text { America }\end{array}$ \\
\hline Boschi-Pinto et al & 2010 & $\begin{array}{l}\text { United States of } \\
\text { America }\end{array}$ \\
\hline Winfrey et al & 2011 & $\begin{array}{l}\text { United States of } \\
\text { America }\end{array}$ \\
\hline Fox et al & 2011 & $\begin{array}{l}\text { United States of } \\
\text { America }\end{array}$ \\
\hline bWalker et al & 2013 & United Sates of America \\
\hline${ }^{a}$ Bollinger et al & 2017 & Unites States of America \\
\hline \multicolumn{3}{|c|}{ Maternal and Neonatal Directed Assessment of Technology model } \\
\hline McClure et al & 2013 & Sub-Saharan Africa \\
\hline bWalker et al & 2013 & United Sates of America \\
\hline \multicolumn{3}{|l|}{ OneHealth Tool } \\
\hline bWalker et al & 2013 & United Sates of America \\
\hline${ }^{\mathrm{a} B o l l i n g e r ~ e t ~ a l ~}$ & 2017 & Unites States of America \\
\hline \multicolumn{3}{|c|}{ Discrete Event Simulation } \\
\hline $\begin{array}{l}\text { Allen and } \\
\text { Wigglesworth }\end{array}$ & 2009 & United Kingdom \\
\hline Goldsman et al & 2009 & United State of America \\
\hline Hamrock et al & 2013 & United State of America \\
\hline
\end{tabular}

be saved after introducing or scaling up interventions as a measure of the impact of interventions as well as an estimate of cost implications for prevented deaths [9, 35, 42, 43].

For any year from 2000 to 2012, LiST has information on mortality, exposures, risk factors, intervention coverage and demography for 90 LMICs [23] . LiST assumes that mortality rates and causes of death would not change considerably from the baseline estimates and that the estimated impact of interventions on mortality are solely due to increase in coverage [23, 46]. Moreover, the tool assumes that quality of service delivery is maintained while increasing coverage [47]. LiST is precise in predicting estimates of the impact of interventions in diverse geographical settings [35, 50-52]. Furthermore, the tool allows users to enter new or future interventions and to assess the impact of new interventions in conjunction with existing interventions in saving lives [23, 26,53 ]. If multiple interventions are evaluated, LiST prevents overestimating the impact of interventions by considering multiple potential causes of deaths and risk factors within one group of deaths [23]. LiST cannot be
Table 2 Author, year of publication and study location of reviewed journal articles that detail application of the reviewed decision support tools for maternal and newborn healthcare

\begin{tabular}{|c|c|c|}
\hline Authors & $\begin{array}{l}\text { Year of } \\
\text { publication }\end{array}$ & Study Location \\
\hline \multicolumn{3}{|l|}{ Lives Saved Tool } \\
\hline Chopra et al & 2009 & South Africa \\
\hline Hazel et al & 2010 & West Africa \\
\hline Bryce et al & 2010 & $\begin{array}{l}\text { Burkina Faso, Ghana and } \\
\text { Malawi }\end{array}$ \\
\hline Friberg et al & 2010 & Sub-Saharan Africa \\
\hline Acuin et al & 2011 & Southeast Asia \\
\hline Pattinson et al & 2011 & International \\
\hline Amouzou et al & 2012 & Niger \\
\hline Walker et al & 2013 & Sub-Saharan Africa \\
\hline Jo et al. & 2014 & Bangladesh and Uganda \\
\hline Johri et al & 2014 & Burkina Faso \\
\hline Homer et al & 2014 & International \\
\hline McPake et al & 2015 & $\begin{array}{l}\text { Ethiopia, Indonesia and } \\
\text { Kenya }\end{array}$ \\
\hline Michalow et al & 2015 & South Africa \\
\hline Chola et al & 2015 & South Africa \\
\hline McGee et al & 2016 & South Africa \\
\hline Keita et al & 2017 & Mali \\
\hline \multicolumn{3}{|c|}{ Maternal and Neonatal Directed Assessment of Technology model } \\
\hline Goldenberg et al & 2014 & Sub-Saharan Africa \\
\hline Kamath-Rayne et al. & 2015 & $\begin{array}{l}\text { Sub-Saharan Africa and } \\
\text { India }\end{array}$ \\
\hline McClure et al & 2015 & Sub-Saharan Africa \\
\hline Harrison et al & 2016 & Sub-Saharan Africa \\
\hline Griffin et al & 2017 & Sub-Saharan Africa \\
\hline Herrick et al & 2017 & Sub-Saharan Africa \\
\hline \multicolumn{3}{|l|}{ OneHealth Tool } \\
\hline Adesina and Bollinger & 2013 & Five African Countries \\
\hline Stenberg et al & 2014 & International \\
\hline Boyle et al & 2015 & International \\
\hline Stenberg et al & 2017 & International \\
\hline Keen et al & 2017 & Sierra Leone \\
\hline \multicolumn{3}{|l|}{ Discrete Event Simulation } \\
\hline Cochran and Bharti & 2006 & United States of America \\
\hline Jacobson et al & 2006 & United States of America \\
\hline Oh and Chow & 2011 & Singapore \\
\hline Zhu Z & 2011 & Singapore \\
\hline Griffin et al & 2012 & Atlanta \\
\hline $\begin{array}{l}\text { Mielczarek and Uzialko- } \\
\text { Mydlikowska }\end{array}$ & 2012 & Poland \\
\hline
\end{tabular}


used to estimate the impact of interventions on perinatal mortality solely, since the assessment of the impact of interventions is limited to the predefined age intervals which do not cover the perinatal period exclusively [26]. LiST has been useful in strategic planning and in identifying interventions that would have highest impact in saving lives and has been applied in LMIC at national, provincial and district levels $[9,47,50,56-58,69]$.

\section{Maternal and neonatal directed assessment of technology model}

The Maternal and Neonatal Directed Assessment of Technology (MANDATE) model enables users to prioritize the allocation of resources towards interventions that have the greatest impact in reducing maternal, fetal and neonatal deaths in low-resource settings, particularly sub-Saharan Africa and India [23, 24, 28, 29]. The MANDATE model was developed by the Research Triangle Institute, with the initial description of its application and its construction published in 2013 [24, 70]. No literature was found presenting further development of the model since its original construction.

The MANDATE model is preloaded with a list of main clinical conditions that contribute to maternal, fetal and neonatal mortality as well as proven methods to prevent, diagnose and treat maternal, fetal and neonatal conditions [24, 29]. Furthermore, the MANDATE model is preloaded with baseline estimates of accessibility, utilization and effectiveness of interventions in specific regions $[24,36]$. All preloaded data were derived from published literature as well as reputable research websites and databases [24, 29, 44]. MANDATE users need to specify the geographic region where intervention will be applied, timeframe of assessment and the intended level of utilization, penetration and efficacy of interventions in order to generate output to guide prioritization of interventions [40]. The tool gives an estimate of the number of maternal, fetal and neonatal lives that could be saved by increasing utilization and penetration of interventions [24, 29, 36, 44, 45].

The MANDATE model assumes that the efficacy of an intervention is the same when applied at home, clinic or in a hospital setting $[28,44]$. The tool can be used to evaluate the impact of one intervention or the impact of a set of integrated interventions and can simulate different scenarios of interventions, enabling comparisons of the impact of different interventions before implementation [36, 44, 54]. The MANDATE model can quantify the effect of maternal conditions on neonatal outcomes [36]. Furthermore, the tool is able to evaluate the impact of preventative, diagnostic and therapeutic technologies as applied in different settings, either at home, clinic or hospital, and can measure the impact of transferring mothers and neonates between different levels of care
[24, 28, 29, 36, 44, 54]. However, the MANDATE output does not distinguish whether neonatal deaths occurred within first 7 days of life or later, and as a result the impact of interventions on perinatal outcomes cannot be measured [40]. The MANDATE model has been implemented in LMIC countries at national and international levels [24, 28, 36, 44, 54, 59, 70].

\section{OneHealth tool}

OneHealth Tool enables users to conduct integrated health system planning and costing for various disease specific programs $[23,25,30]$. The OneHealth Tool was developed by the United Nations Interagency Working Group on Costing and was first released in 2012 [71]. During its initial release, OneHealth Tool had planning and costing components for the following disease programs: Tuberculosis, Malaria, Immunization, Water and Sanitation, Reproductive Health, Nutrition and Child Health [71]. No further development of the OneHealth Tool regarding planning and costing of programs relating to maternal, neonatal and child health has been published since its original construction.

OneHealth Tool has incorporated pre-existing United Nations epidemiological reference group models including the LiST, AIM and the Fam Plan model [23, 30, 6062]. Fam Plan estimates the impact of scaling up family planning on fertility [23]. Thus, OneHealth Tool has access to epidemiological and demographic data that is preloaded in the United Nations epidemiological reference group models [37]. OneHealth Tool users are required to specify the geographical region for which integrated planning and costing is conducted, the current state of the building blocks of the health system, and the settings in which interventions will be implemented [37]. OneHealth Tool provides estimates of the number of health care professionals needed to implement interventions, medical resources needed for implementation of interventions, expected costs necessary for proper implementation of interventions, as well as number of lives that could be saved by implementing interventions $[30,37,41]$.

OneHealth Tool assumes that interventions are delivered in one or more of the following settings: directly to the community, through an outreach program, in clinics and in hospitals [41]. OneHealth Tool can perform a consolidated analysis across different disease programs while assessing the impact of implementing interventions on the functioning of the health system and also evaluating feasibility of sustaining interventions with regard to available finances [30]. Moreover, OHT incorporates costing of selected non-health sector factors that may have an impact on health outcomes [37]. Although OneHealth Tool is useful in planning for maternal and newborn health programs, it does not measure the 
Table 3 Online videos detailing development and application of the identified decision support tools maternal and newborn healthcare

\begin{tabular}{|c|c|c|c|}
\hline $\begin{array}{l}\text { Decision Support } \\
\text { Tool }\end{array}$ & Author & Title & website \\
\hline Lives Saved Tool & Lives Saved Tool & $\begin{array}{l}\text { Software demonstration - } \\
\text { Subnational Wizard }\end{array}$ & https://www.youtube.com/watch?v=ITZxCJbK8tE \\
\hline \multirow[t]{2}{*}{ MANDATE Model } & MANDATE & Overview of MANDATE & $\begin{array}{l}\text { http://www.mandate4mnh.org/content/media_overview/ } \\
\text { index.html }\end{array}$ \\
\hline & MANDATE & Using the MANDATE Web Model & $\begin{array}{l}\text { http://www.mandate4mnh.org/content/media_tutorial/ } \\
\text { index.html }\end{array}$ \\
\hline OneHealth Tool & $\begin{array}{l}\text { Harmonization for Health } \\
\text { in Africa }\end{array}$ & Introduction on the "One Health Tool & https://www.youtube.com/watch?v=19ix5oZ6ETk \\
\hline OneHealth Tool & $\begin{array}{l}\text { Harmonization for Health } \\
\text { in Africa }\end{array}$ & $\begin{array}{l}\text { Tutorial on how to use the OneHealth } \\
\text { Tool }\end{array}$ & https://www.youtube.com/watch?v=t1chFnEH9nl \\
\hline
\end{tabular}

impact of interventions on perinatal outcomes as the output does not indicate the period when neonatal deaths occurred [37]. Currently, OneHealth Tool is used globally for planning and costing at a national level [23, $37,61-63,71]$.

\section{Discrete event simulation}

Discrete Event Simulation (DES) is a statistically based tool that is used to assess the efficiency of a healthcare delivery system and to forecast the potential impact of implementing changes in the healthcare delivery system $[22,31]$. DES was initially developed as part of the General Simulation Program (GSP) in the mid-40s [72]. The GSP is a general-purpose simulator which was primarily developed to implement simulations in an industrial setting $[72,73]$. Since its initial design, DES has been used in diverse settings including the healthcare system $[48,49]$.

To initiate simulation, a DES user needs to understand and map the structure and the processes involved in healthcare delivery [64]. Essentially, the user needs to specify the current operational state of the health system with regards to number of service stations, number of health professionals available in each service station, medical resources available, time taken in each service station, arrival rates and service times [22]. DES generates performance measures of the healthcare system according to the user's specifications. The commonly generated performance measures are patient throughput, timeliness of care and resource utilization [22].

The DES assumes that the clients arrive at a health facility in a time-dependent pattern and the state of the health system changes as clients arrive $[48,49]$. DES imitates the operation of the real world system and shows how processes interact as a whole in the system, providing a macro-level view [22]. It is able to model several processes that occur simultaneously in a health care system [55]. For instance, it can incorporate interdependent queues that clients may need to follow in a health facility. DES has been found useful in the allocation of scarce resources while minimizing healthcare delivery costs [31]. It has been used effectively for various healthcare delivery needs, including improvement of patient flow, managing bed capacity, scheduling staff, managing patient admission and in the use of laboratories and pharmacies [22, 48]. DES has been utilized in $\mathrm{HIC}$, at health facility level [31, 48, 49, 55, 64, 65].

\section{Discussion}

This literature review was conducted to identify decision support tools that could be applied at district hospital level to strengthen decision-making in the health system for perinatal care in South Africa. Four decision support tools were identified and reviewed, namely the Lives Saved Tool (LisT), Maternal and Neonatal Directed Assessment of Technology (MANDATE), OneHealth Tool and Discrete Event Simulation (DES) [22-25]. Both LiST and the MANDATE model were designed to support health managers in prioritizing interventions for pregnancy related health issues, primarily at national level $[23,24]$. For instance, LiST has been utilized to identify a set of interventions that could save more lives of pregnant women and children and also prevent stillbirths [35]. Similarly, the MANDATE model has been used to estimate maternal deaths, surgeries, and cases of severe anemia prevented through the use of uterine balloon tamponade among women with postpartum haemorrhage [70]. OneHealth Tool enables health managers at national level to conduct an integrated health system planning and costing for various disease programs including reproductive health and child health programs [71]. The Discrete Event Simulation was designed to assist managers improve operational issues at a health facility level [22, 48, 49].

Measurement challenges for the perinatal period were noted in estimates generated by the LiST, MANDATE Model and OneHealth Tool. These tools provide estimates of the impact of interventions on neonatal deaths in predefined age intervals $[26,37,40]$. The limitation of 
Table 4 Summary of the features of reviewed decision support tools

\begin{tabular}{|c|c|c|}
\hline Tool & Lives Saved Tool & MANDATE model \\
\hline Purpose & $\begin{array}{l}\text { Estimate the impact of } \\
\text { introducing or increasing } \\
\text { coverage of maternal, neonatal } \\
\text { and child health interventions } \\
\text { on mortality }[23,25-27]\end{array}$ & $\begin{array}{l}\text { Guide users to prioritize } \\
\text { allocation of resources towards } \\
\text { interventions that have greatest } \\
\text { impact in reducing maternal, } \\
\text { fetal and neonatal mortality [23, } \\
24,28,29]\end{array}$ \\
\hline $\begin{array}{l}\text { Preloaded } \\
\text { Data }\end{array}$ & $\begin{array}{l}\text { a) List of maternal, neonatal and } \\
\text { child health interventions [ } 23 \text {, } \\
26,32] \\
\text { b) Estimated baseline coverage } \\
\text { of interventions at national level } \\
{[23,26,27,33,34]} \\
\text { c) Recent estimate of the } \\
\text { effectiveness of interventions } \\
\text { that are introduced or scaled up } \\
\text { [26, 33] } \\
\text { d) Population risk factors and } \\
\text { causes of death relating to } \\
\text { maternal, neonatal and child }\end{array}$ & $\begin{array}{l}\text { a) List of main clinical } \\
\text { conditions that contribute to } \\
\text { maternal, fetal and neonatal } \\
\text { mortality }[24,29] \\
\text { b) Clinically proven methods to } \\
\text { prevent, diagnose and treat } \\
\text { maternal, fetal and neonatal } \\
\text { conditions [29] } \\
\text { c) Baseline estimates of } \\
\text { utilization, penetration and } \\
\text { efficacy of interventions at a } \\
\text { national or international level } \\
{[24,36]}\end{array}$ \\
\hline
\end{tabular}

Required a) Geographical region where

Input interventions will be applied [38]

b) Projected coverage of interventions to be assessed [26, 34, 39]

c) Measures of maternal, neonatal and child health status at national level [26]

Generated output

a) Estimated number of lives that could be saved by introducing or by increasing coverage of maternal, neonatal and child interventions $[9,35$, 42, 43]

b) Cost implications for prevented deaths $[35,42,43]$

Assumptions a) Mortality rates and causes of death would not change considerably from the baseline estimates [23]

b) Estimated impact of interventions on mortality are solely due to the increase in coverage $[23,46]$

c) Quality of care is maintained while increasing coverage [47]

Strengths a) Provides accurate predictions of neonatal and child mortality in diverse geographical settings $[35,50-52]$

b) Models the impact of a single or integrated a) Timeframe of assessment [40] a) Geographical region for b) Geographical region where which integrated planning and intervention will be applied [40] costing is conducted [37]

c) Intended levels of utilization, b) Current state of the building penetration and efficacy in different settings, either at home, clinic and or in hospital [40]

blocks of the health system [30, 37]

c) Coverage targets and disease program costs [30]

d) Settings in which interventions will be implemented, whether it is through community based programs, community health centers, hospitals or national level $[37,41]$

Estimated number of lives saved by increasing utilization and penetration of maternal, fetal and neonatal interventions 37$]$ $[24,29,36,44,45]$

a) Number of health care professionals needed to implement intervention(s) [30, 37]

b) Medical resources needed for implementation of interventions $[30,37]$

c) Expected costs necessary for proper implementation of interventions $[25,30,37]$

d) Number of lives that could be saved by implementing interventions [30, 37]

Efficacy of interventions is the same in different levels of care (i.e. home, clinic or hospital) [28, 44]

Interventions applied in one or more of the following settings:

a) Community

b) Outreach

c) Clinic

d) Hospital [41]
Current operational state of the health system [22]

a) Number of service stations

b) Number of health

professionals available in each service station

c) Medical resources available

d) Arrival rates

e) Service times

Performance measures specified by the user such as patient throughput, timeliness of care and resource utilization [22]

Simulation changes at a discrete time interval $[48,49]$ a) Evaluates the impact of single and integrated interventions [36]

b) Evaluates the impact of different types of interventions (preventative, diagnostic and a) Enables a consolidated analysis across programs while considering financial capacity of the health system [30]

b) Incorporates costing of selected non-health sector a) Shows how processes interact as a whole in the system, providing a macro-level view [22] b) Models several processes that occur simultaneously in a health 
Table 4 Summary of the features of reviewed decision support tools (Continued)

\begin{tabular}{|c|c|c|c|c|}
\hline Tool & Lives Saved Tool & MANDATE model & OneHealth Tool & Discrete Event Simulation \\
\hline & $\begin{array}{l}\text { interventions }[23,26,53] \\
\text { c) Avoids overestimating the } \\
\text { impact of interventions by } \\
\text { considering multiple potential } \\
\text { causes of deaths and risk factors } \\
\text { within one group of deaths [23] }\end{array}$ & $\begin{array}{l}\text { treatment) }[24,28,36,44,54] \\
\text { c) Assesses the impact of } \\
\text { transferring mothers and } \\
\text { neonates between different } \\
\text { levels of care }[24,28,36,44]\end{array}$ & $\begin{array}{l}\text { factors that may have an impact } \\
\text { on health outcomes [37] }\end{array}$ & $\begin{array}{l}\text { care system [55] } \\
\text { c) Effective in allocating scarce } \\
\text { resources while minimizing } \\
\text { healthcare delivery costs [31] }\end{array}$ \\
\hline Limitations & $\begin{array}{l}\text { Assessment of impact of } \\
\text { interventions is limited to the } \\
\text { predefined age intervals which } \\
\text { do not cover the perinatal } \\
\text { period exclusively [26] }\end{array}$ & $\begin{array}{l}\text { Output does not distinguish } \\
\text { whether neonatal deaths } \\
\text { occurred within the first } 7 \text { days } \\
\text { of life or later, as a result the } \\
\text { impact of interventions on } \\
\text { perinatal outcomes cannot be } \\
\text { measured [40] }\end{array}$ & $\begin{array}{l}\text { Output does not distinguish } \\
\text { whether neonatal deaths } \\
\text { occurred within the first } 7 \text { days } \\
\text { of life or later, as a result the } \\
\text { impact of interventions on } \\
\text { perinatal outcomes cannot be } \\
\text { measured [37] }\end{array}$ & Not specified \\
\hline $\begin{array}{l}\text { Settings } \\
\text { where tool } \\
\text { has been } \\
\text { applied }\end{array}$ & $\begin{array}{l}\text { Low- and middle-income coun- } \\
\text { tries }[9,33-35,42,46,47,50-53 \\
56-58]\end{array}$ & $\begin{array}{l}\text { Low- and middle-income coun- } \\
\text { tries }[28,36,44,45,54,59]\end{array}$ & $\begin{array}{l}\text { Low, middle and high income } \\
\text { countries }[25,60-63]\end{array}$ & $\begin{array}{l}\text { High-income countries }[31,48, \\
49,55,64,65]\end{array}$ \\
\hline $\begin{array}{l}\text { Level of } \\
\text { application }\end{array}$ & $\begin{array}{l}\text { Country, provincial and district } \\
\text { level }[9,33,34,42,46,47,50-53 \text {, } \\
56-58]\end{array}$ & $\begin{array}{l}\text { National and international }[28, \\
36,44,45,54,59]\end{array}$ & National $[25,60-63]$ & $\begin{array}{l}\text { Facility level [31, 48, 49, 55, 64, } \\
65]\end{array}$ \\
\hline
\end{tabular}

the generated outputs is that estimates do not distinguish if deaths occurred in the first 7 days of life or later $[26,37,40]$. Consequently, the impact of interventions on perinatal outcomes cannot be estimated.

None of the identified decision support tools can be adopted at district hospital level to strengthen decisionmaking in the health system for perinatal care in South Africa. The LiST, MANDATE Model and OneHealth Tool were not designed for implementation at facility level and have limitations in estimating the impact of interventions for the perinatal period $[23,24,26,37,40$, 71]. DES is indeed applicable at facility level; however, it was designed to guide managers improve operational issues of a health system and has not been applied to improve health outcomes of a disease-specific program [22, $48,49]$. Thus, the reviewed decision support tools should be enhanced prior to implementation in the health system for perinatal care in district hospitals in South Africa.

The reviewed decision support tools have been successfully implemented in LMIC and in HIC settings in prioritizing interventions for maternal, child and neonatal health issues [24, 28, 35, 48, 57]. The LiST and the MANDATE model were specifically designed for implementation in LMIC and have been successfully implemented in these settings $[9,52]$. The OneHealth Tool has been utilized for various disease programs in LMIC and in HIC $[25,30]$. The DES, which is applied at facility level, has only been applied to improve the functioning of obstetric units and primary health care facilities in HIC [48, 64]. Thus, through the application of OneHealth Tool and DES in HIC, decision-making by health managers has been supported at higher levels of management and at facility level. Certainly, improved perinatal outcomes in HIC cannot be solely attributed to the availability and implementation of decision support tools in health facilities. However, health systems in LMIC would benefit from the development and implementation of decision support tools that can be applied at health facility level specifically to strengthen perinatal care.

Poor health system functioning is the main contributor to high perinatal mortality in South Africa $[10,11]$. Hence, a decision support tool relevant for implementation in district hospitals should incorporate the elements to address the performance of the health system essential for optimal perinatal care. Particularly in district hospitals, the tool should guide facility managers in optimal allocation of limited financial resources and in optimising efficiencies. Hence, the tool needs to provide guidance with regard to health system components that need to be prioritized. For instance, informed guidance is needed to decide whether priority is given to purchasing of medical equipment, buying essential medicines, hiring additional staff, provision of relevant training to staff, or in strengthening health information systems. Overall, integrating health system performance in a decision support tool will ensure that managers get a holistic view of all health system factors that influence perinatal outcomes.

The Negotiated Service Delivery Agreement in South Africa emphasized the need to strengthen all critical building blocks of the health system in order to improve its performance [74]. Moreover, the recommendations made by the National Perinatal Morbidity and Mortality Committee (NaPeMMCo), regarding essential strategies to decrease perinatal deaths in South Africa, focused on strengthening the health system [11]. Remarkably, the majority of recommendations made by NaPeMMCo 
were intended to be implemented in health facilities [11]. Therefore, it is important that the health system for perinatal care is strengthened at a facility level in order to reduce the burden of perinatal mortality.

The function of managers in health facilities need to be strengthened to ensure proper implementation of available guidelines. Particularly in district hospitals, stronger leadership and greater local accountability is key to improving quality of care [9]. Certainly, the function of managers in district hospitals in South Africa can be strengthened by introducing the use of a relevant and contextualized decision support tool that incorporates the performance of the health system at facility level for optimal perinatal care. However, existing tools could be adapted for implementation in district hospitals. In particular, the OneHealth Tool appears to be the most relevant tool to be considered for adaption for implementation in district hospitals as it is useful in integrating health system planning and costing $[23,25,30]$. Moreover, it incorporates a majority of health system building blocks in planning [30, 37]. Hence, adaptation of OneHealth Tool for use in health facilities could be beneficial.

\section{Conclusion}

The reviewed decision support tools have been useful in supporting decision-making in the health sector. However, none of the reviewed tools could be adopted at district hospital level to strengthen the health system for perinatal care in South Africa. Therefore, there is a need for existing decision support tools to be adapted for implementation at facility level or for research to be conducted to develop a tool that will support decisionmaking at district hospital level towards strengthening the health system for perinatal care in South Africa. Nevertheless, availability and implementation of a relevant decision support tool will only yield positive perinatal outcomes provided that there are improvements in management, education and in cultural change.

\section{Abbreviations}

AIM: Aids Impact Model; DES: Discrete Event Simulation; GSP: General Simulation Program; HIC: High-income countries; LiST: Lives Saved Tool; LMIC: Low- and middle-income countries; MANDATE: Maternal and Neonatal Directed Assessment of Technology; NaPeMMCo: National Perinatal Morbidity and Mortality Committee

\section{Acknowledgements \\ I would like to acknowledge the University of KwaZulu-Natal for enabling easy access to electronic databases from which research articles were extracted.}

\section{Authors' contributions}

NMN acquired articles for review, synthesis findings from articles, wrote the first draft of the manuscript, wrote the final version of the manuscript and is accountable for all aspects of the manuscript. ASV had a substantial contribution in the conception and design of the study, critically revised the first draft, approved final version of the manuscript and agreed to be accountable for all aspects of the manuscript. Both authors read and approved the final manuscript.

\section{Funding}

This study was supported by the University of KwaZulu-Natal College of Health Sciences Scholarship and the Research Methodology PhD Support Programme. The funding organisations did not participate in the study.

\section{Availability of data and materials}

The reviewed literature analysed during the current review are available from the corresponding author on reasonable request.

\section{Ethics approval and consent to participate}

This study was ethically reviewed and approved by the University of KwaZulu-Natal Biomedical Research Ethics Committee (approval number BE005/15). This is a literature review, there were no study participants. Hence consent to participate was not necessary.

\section{Consent for publication}

Not applicable, no individual data was used.

\section{Competing interests}

The authors declare that they have no competing interests.

Received: 25 March 2019 Accepted: 9 October 2019

Published online: 22 October 2019

References

1. Akseer N, Lawn JE, Keenan W, Konstantopoulos A, Cooper P, Ismail Z, Thacker N, Cabral S, Bhutta ZA. Ending preventable newborn deaths in a generation. Int J Gynecol Obstet. 2015;131:S43-8.

2. Lawn JE, Blencowe H, Pattinson R, Cousens S, Kumar R, Ibiebele I, Gardosi J, Day LT, Stanton C. Stillbirths: where? when? why? how to make the data count? Lancet. 2011;377(9775):1448-63.

3. Blencowe H, Cousens S, Jassir FB, Say L, Chou D, Mathers C, Hogan D, Shiekh S, Qureshi ZU, You D. National, regional, and worldwide estimates of stillbirth rates in 2015, with trends from 2000: a systematic analysis. Lancet Glob Health. 2016:4(2):e98-e108.

4. Lawn JE, Cousens S, Zupan J, Team LNSS. 4 million neonatal deaths: when? where? why? Lancet. 2005;365(9462):891-900.

5. Heazell AE, Siassakos D, Blencowe H, Burden C, Bhutta ZA, Cacciatore J, Dang N, Das J, Flenady V, Gold KJ. Stillbirths: economic and psychosocial consequences. Lancet. 2016;387(10018):604-16.

6. Kelley MC, Trinidad SB. Silent loss and the clinical encounter: parents' and physicians' experiences of stillbirth-a qualitative analysis. BMC Pregnancy Childbirth. 2012;12(1):137.

7. Mashego T-AB, Nesengani DS, Ntuli T, Wyatt G. Burnout, compassion fatigue and compassion satisfaction among nurses in the context of maternal and perinatal deaths. J Psychol Afr. 2016:26(5):469-72.

8. Nuzum D, Meaney S, O'donoghue K. The impact of stillbirth on consultant obstetrician gynaecologists: a qualitative study. BJOG Int J Obstet Gynaecol. 2014;121(8):1020-8.

9. Chopra M, Daviaud E, Pattinson R, Fonn S, Lawn JE. Saving the lives of South Africa's mothers, babies, and children: can the health system deliver? Lancet. 2009;374(9692):835-46.

10. Saving babies 2012-2013. In: Pattinson R, Rhoda N, editors. Ninth report on perinatal care in South Africa. Pretoria: Tshepesa Press; 2014.

11. Number of Perinatal Deaths According to District Health Information System (DHIS). In: National Perinatal Mortality and Morbidity Committe (NaPeMMCo) Triennial Report (2008-2010). Pretoria: National Perinatal Mortality and Morbidity Committee; 2011.

12. National Perinatal Mortality and Morbidity Committe. Saving babies 20142016: triennial report on perinatal mortality in South Africa. Pretoria: National Department of Health; 2018.

13. Allanson ER, Pattinson RC. Quality-of-care audits and perinatal mortality in South Africa. Bull World Health Organ. 2015;93:424-8.

14. Pattinson R, PPIP Group. Saving babies 2008-2009: seventh report on perinatal care in South Africa. Edited by Group P. Pretoria: Tshepesa Press; 2011

15. National Perinatal Morbidity and Mortality Committee. National perinatal morbidity and mortality committee report 2008-2010. Pretoria: South African National Department of Health; 2011. 
16. Pattinson RC, Makin JD, Pillay Y, van den Broek N, Moodley J. Basic and comprehensive emergency obstetric and neonatal care in 12 South African health districts. S Afr Med J. 2015;105(4):256-60.

17. Coovadia H, Jewkes R, Barron P, Sanders D, Mclntyre D. The health and health system of South Africa: historical roots of current public health challenges. Lancet. 2009;374(9692):817-34.

18. English R, Masilela T, Barron P, Schönfeldt A. Health information systems in South Africa. South African health review; 2011.

19. Scott V, Gilson L. Exploring how different modes of governance act across health system levels to influence primary healthcare facility managers' use of information in decision-making: experience from Cape Town, South Africa. Int J Equity Health. 2017;16(1):159.

20. Pickering $C$, Byrne J. The benefits of publishing systematic quantitative literature reviews for PhD candidates and other early-career researchers. High Educ Res Dev. 2014;33(3):534-48.

21. Pickering C, Grignon J, Steven R, Guitart D, Byrne J. Publishing not perishing: how research students transition from novice to knowledgeable using systematic quantitative literature reviews. Stud High Educ. 2015;40(10):1756-69.

22. Hamrock E, Paige K, Parks J, Scheulen J, Levin S. Discrete event simulation for healthcare organizations: a tool for decision making. J Healthc Manag. 2013:58(2):110-25.

23. Walker N, Tam Y, Friberg IK. Overview of the lives saved tool (LiST). BMC Public Health. 2013;13(Suppl 3):S1.

24. McClure EM, Rouse DJ, MacGuire ER, Jones B, Griffin JB, Jobe AH, Kamath-Rayne BD, Shaffer C, Goldenberg RL. The MANDATE model for evaluating interventions to reduce postpartum hemorrhage. Int J Gynecol Obstet. 2013;121(1):5-9.

25. Adesina A, Bollinger LA. Estimating the cost-savings associated with bundling maternal and child health interventions: a proposed methodology. BMC Public Health. 2013;13(3):1.

26. Winfrey W, McKinnon R, Stover J. Methods used in the lives saved too (LiST). BMC Public Health. 2011;11(3):1

27. Boschi-Pinto C, Young M, Black RE. The Child Health Epidemiology Reference Group reviews of the effectiveness of interventions to reduce maternal, neonatal and child mortality. Int J Epidemiol. 2010;39(suppl 1):i3-6.

28. Kamath-Rayne BD, Griffin JB, Moran K, Jones B, Downs A, McClure EM, Goldenberg RL, Rouse D, Jobe AH. Resuscitation and obstetrical care to reduce intrapartum-related neonatal deaths: a MANDATE study. Matern Child Health J. 2015;19(8):1853-63.

29. MANDATE OVERVIEW. http://www.mandate4mnh.org/content/media_ overview/index.html. Accessed 20 June 2016.

30. Bollinger LA, Sanders R, Winfrey W, Adesina A. Lives saved tool (LiST) costing: a module to examine costs and prioritize interventions. BMC Public Health. 2017;17(4):782

31. Jacobson SH, Hall SN, Swisher JR. Discrete-event simulation of health care systems. In: Patient flow: reducing delay in healthcare delivery. Boston: Springer; 2006. p. 211-52.

32. Friberg IK, Bhutta ZA, Darmstadt GL, Bang A, Cousens S, Baqui AH, Kumar V, Walker N, Lawn JE. Comparing modelled predictions of neonatal mortality impacts using LiST with observed results of community-based intervention trials in South Asia. Int J Epidemiol. 2010;39(suppl 1):i11-20.

33. Friberg IK, Kinney MV, Lawn JE, Kerber KJ, Odubanjo MO, Bergh A-M, Walker N, Weissman E, Chopra M, Black RE. Sub-Saharan Africa's mothers, newborns, and children: how many lives could be saved with targeted health interventions? PLoS Med. 2010;7(6):e1000295.

34. Pattinson R, Kerber K, Buchmann E, Friberg IK, Belizan M, Lansky S, Weissman E, Mathai M, Rudan I, Walker N. Stillbirths: how can health systems deliver for mothers and babies? Lancet. 2011;377(9777):1610-23.

35. McGee S-A, Chola L, Tugendhaft A, Mubaiwa V, Moran N, McKerrow N, Kamugisha L, Hofman K. Strategic planning for saving the lives of mothers, newborns and children and preventing stillbirths in KwaZulu-Natal province South Africa: modelling using the lives saved tool (LiST). BMC Public Health. 2016;16(1):1.

36. Goldenberg RL, Jones B, Griffin JB, Rouse DJ, Kamath-Rayne BD, Trivedi N, McClure EM. Reducing maternal mortality from preeclampsia and eclampsia in low-resource countries-what should work? Acta Obstet Gynecol Scand. 2015;94(2):148-55

37. Tutorial on how to use OneHealth Tool. https://www.youtube.com/ watch? $v=t 1$ chFnEH9nl. Accessed 26 June 2016.

38. Lives Saved Tool. Software demonstration - Subnational Wizard. https:// www.youtube.com/watch?v=ITZxCJbK8tE. Accessed 3 Oct 2019.

39. Lawn JE, Kinney M, Lee AC, Chopra M, Donnay F, Paul VK, Bhutta ZA, Bateman M, Darmstadt GL. Reducing intrapartum-related deaths and disability: can the health system deliver? Int J Gynaecol Obstet. 2009; 107(Supplement 1):S123-40, S140-2

40. Using the MANDATE Web Model. http://www.mandate4mnh.org/content/ media tutorial/index.html. Accessed 20 June 2016.

41. OneHealth Tool Intervention Assumptions. http://avenirhealth.org/ Download/Spectrum/Manuals/Treatment\%20Assumptions\%202016\%201\%2 010.pdf. Accessed 18 May 2017

42. Chola L, Pillay Y, Barron P, Tugendhaft A, Kerber K, Hofman K. Cost and impact of scaling up interventions to save lives of mothers and children: taking South Africa closer to MDGs 4 and 5. Glob Health Action. 2015;8(1):27265.

43. Bartlett L, Weissman E, Gubin R, Patton-Molitors R, Friberg IK. The impact and cost of scaling up midwifery and obstetrics in 58 low-and middleincome countries. PLoS One. 2014;9(6):e98550.

44. Harrison MS, Griffin JB, McClure EM, Jones B, Moran K, Goldenberg RL. Maternal Mortality from obstructed labor: a MANDATE analysis of the ability of technology to save lives in sub-Saharan Africa. Am J Perinatol. 2016;33(09):873-81.

45. Herrick TM, Harner-Jay CM, Levisay AM, Coffey PS, LaBarre PD. Prioritizing investments in innovations to protect women from the leading causes of maternal death. BMC Pregnancy Childbirth. 2014;14(1):1.

46. Walker N, Yenokyan G, Friberg IK, Bryce J. Patterns in coverage of maternal, newborn, and child health interventions: projections of neonatal and under5 mortality to 2035. Lancet. 2013;382(9897):1029-38.

47. Bryce J, Friberg IK, Kraushaar D, Nsona H, Afenyadu GY, Nare N, Kyei-Faried S, Walker N. LiST as a catalyst in program planning: experiences from Burkina Faso, Ghana and Malawi. Int J Epidemiol. 2010;39(suppl 1):i40-7.

48. Griffin J, Xia S, Peng S, Keskinocak P. Improving patient flow in an obstetric unit. Health Care Manag Sci. 2012;15(1):1-14.

49. Cochran JK, Bharti A. Stochastic bed balancing of an obstetrics hospital. Health Care Manag Sci. 2006;9(1):31-45.

50. Hazel E, Gilroy K, Friberg I, Black RE, Bryce J, Jones G. Comparing modelled to measured mortality reductions: applying the lives saved tool to evaluation data from the accelerated child survival Programme in West Africa. Int J Epidemiol. 2010;39(suppl 1):i32-9.

51. Johri M, Ridde V, Heinmüller R, Haddad S. Estimation of maternal and child mortality one year after user-fee elimination: an impact evaluation and modelling study in Burkina Faso. Bull World Health Organ. 2014:92(10):706-15.

52. Michalow J, Chola L, McGee S, Tugendhaft A, Pattinson R, Kerber K, Hofman K. Triple return on investment: the cost and impact of 13 interventions that could prevent stillbirths and save the lives of mothers and babies in South Africa. BMC Pregnancy Childbirth. 2015;15(1):39.

53. Jo $Y$, Labrique $A B$, Lefevre $A E$, Mehl G, Pfaff $T$, Walker N, Friberg IK. Using the lives saved tool (LiST) to model mHealth impact on neonatal survival in resource-limited settings. PLoS One. 2014;9(7):e102224.

54. McClure EM, Jones B, Rouse DJ, Griffin JB, Kamath-Rayne BD, Downs A, Goldenberg RL. Tranexamic acid to reduce postpartum hemorrhage: a MANDATE systematic review and analyses of impact on maternal mortality. Am J Perinatol. 2015;32(05):469-74.

55. Mielczarek B, Uziałko-Mydlikowska J. Application of computer simulation modeling in the health care sector: a survey. Simulation. 2012:88(2):197-216.

56. McPake B, Edoka I, Witter S, Kielmann K, Taegtmeyer M, Dieleman M, Vaughan K, Gama E, Kok M, Datiko D. Cost-effectiveness of communitybased practitioner programmes in Ethiopia, Indonesia and Kenya. Bull World Health Organ. 2015:93(9):631-9.

57. Acuin CS, Khor GL, Liabsuetrakul T, Achadi EL, Htay TT, Firestone R, Bhutta ZA. Maternal, neonatal, and child health in Southeast Asia: towards greater regional collaboration. Lancet. 2011;377(9764):516-25.

58. Keita $Y$, Sangho $H$, Roberton $T$, Vignola $E$, Traoré M, Munos M. Using the lives saved tool to aid country planning in meeting mortality targets: a case study from Mali. BMC Public Health. 2017;17(4):777.

59. Griffin JB, McClure EM, Kamath-Rayne BD, Hepler BM, Rouse DJ, Jobe AH, Goldenberg RL. Interventions to reduce neonatal mortality: a mathematical model to evaluate impact of interventions in sub-Saharan Africa. Acta Paediatr. 2017;106(8):1286-95.

60. Stenberg $\mathrm{K}$, Axelson $\mathrm{H}$, Sheehan $\mathrm{P}$, Anderson I, Gülmezoglu AM, Temmerman M, Mason E, Friedman HS, Bhutta ZA, Lawn JE. Advancing social and economic development by investing in women's and children's health: a new global investment framework. Lancet. 2014; 383(9925):1333-54.

61. Boyle CF, Levin C, Hatefi A, Madriz S, Santos N. Achieving a "grand convergence" in global health: modeling the technical inputs, costs, and impacts from 2016 to 2030. PLoS One. 2015;10(10):e0140092. 
62. Stenberg K, Hanssen O, Edejer TT-T, Bertram M, Brindley C, Meshreky A, Rosen JE, Stover J, Verboom P, Sanders R. Financing transformative health systems towards achievement of the health sustainable development goals: a model for projected resource needs in 67 low-income and middleincome countries. Lancet Glob Health. 2017;5(9):e875-87.

63. Keen $\mathrm{S}$, Begum $\mathrm{H}$, Friedman $\mathrm{HS}$, James CD. Scaling up family planning in Sierra Leone: a prospective cost-benefit analysis. Womens Health. 2017; 13(3):43-57.

64. Oh $\mathrm{H}$, Chow W. Scientific evaluation of polyclinic operating strategies with discrete-event simulation. Int J Simul Model. 2011;10(4):165-76.

65. Zhu Z. Impact of different discharge patterns on bed occupancy rate and bed waiting time: a simulation approach. J Med Eng Technol. 2011;35(6-7):338-43.

66. Jones G, Steketee RW, Black RE, Bhutta ZA, Morris SS, Group BCSS. How many child deaths can we prevent this year? Lancet. 2003;362(9377):65-71.

67. Amouzou A, Habi O, Bensaïd K, Group NCCSW. Reduction in child mortality in Niger: a countdown to 2015 country case study. Lancet. 2012;380(9848): 1169-78.

68. Homer CS, Friberg IK, Dias MAB, ten Hoope-Bender P, Sandall J, Speciale AM, Bartlett LA. The projected effect of scaling up midwifery. Lancet. 2014; 384(9948):1146-57.

69. Fox MJ, Martorell R, van den Broek N, Walker N. Assumptions and methods in the lives saved tool (LiST). BMC Public Health. 2011;11(3):1.

70. Herrick T, Mvundura M, Burke TF, Abu-Haydar E. A low-cost uterine balloon tamponade for management of postpartum hemorrhage: modeling the potential impact on maternal mortality and morbidity in sub-Saharan Africa. BMC Pregnancy Childbirth. 2017;17(1):374

71. Introduction on the "One Health Tool". https://www.youtube.com/watch?v= I9ix5oZ6ETk. Accessed 20 June 2016.

72. Goldsman D, Nance RE, Wilson JR. A brief history of simulation. In: Winter simulation conference; 2009. p. 310-3.

73. Allen M, Wigglesworth M. Innovation leading the way: application of lean manufacturing to sample management. J Biomol Screen. 2009;14(5):515-22.

74. Day C, Gray A, Budgell E. Health and related indicators. South Afr Health Rev. 2011;2011(1):119-248.

\section{Publisher's Note}

Springer Nature remains neutral with regard to jurisdictional claims in published maps and institutional affiliations.

Ready to submit your research? Choose BMC and benefit from:

- fast, convenient online submission

- thorough peer review by experienced researchers in your field

- rapid publication on acceptance

- support for research data, including large and complex data types

- gold Open Access which fosters wider collaboration and increased citations

- maximum visibility for your research: over $100 \mathrm{M}$ website views per year

At $\mathrm{BMC}$, research is always in progress.

Learn more biomedcentral.com/submissions 